\title{
Clinical utility of chest radiography for severe COVID-19
}

\author{
Terrence C. H. Hui ${ }^{1} \wedge$, Hau Wei Khoo ${ }^{1 \wedge}$, Barnaby E. Young ${ }^{2,3,4}$, Salahudeen Mohamed Haja Mohideen ${ }^{5}$, \\ Yeong Shyan Lee ${ }^{1}$, Chien Joo Lim ${ }^{6}$, Yee Sin Leo ${ }^{2,3,4,7,8}$, Gregory J. L. Kaw ${ }^{1}$, David C. Lye ${ }^{2,3,4,7}$, \\ Cher Heng $\operatorname{Tan}^{1,4} \wedge$
}

${ }^{1}$ Department of Diagnostic Radiology, Tan Tock Seng Hospital, Singapore, Singapore; ${ }^{2}$ National Centre for Infectious Diseases, Singapore, Singapore; ${ }^{3}$ Department of Infectious Diseases, Tan Tock Seng Hospital, Singapore, Singapore; ${ }^{4}$ Lee Kong Chian School of Medicine, Singapore, Singapore; ${ }^{5}$ Department of Diagnostic Radiology, Singapore General Hospital, Singapore, Singapore; ${ }^{6}$ Clinical Research \& Innovations Office, Tan Tock Seng Hospital, Singapore, Singapore; ${ }^{7}$ Yong Loo Lin School of Medicine, National University of Singapore, Singapore, Singapore; ${ }^{8}$ Saw Swee Hock School of Public Health, National University of Singapore, Singapore, Singapore

Correspondence to: Cher Heng Tan. Department of Diagnostic Radiology, Tan Tock Seng Hospital, 11 Jalan Tan Tock Seng, Singapore 308433, Singapore; Lee Kong Chian School of Medicine, 11 Mandalay Rd, Singapore 308232, Singapore. Email: cher_heng_tan@ttsh.com.sg.

Background: Chest radiography (CXR) is performed more widely and readily than CT for the management of coronavirus disease (COVID-19), but there remains little data on its clinical utility. This study aims to assess the diagnostic performance of CXR, with emphasis on its predictive value, for severe COVID-19 disease.

Methods: A retrospective cohort study was conducted, 358 chest radiographs were performed on 109 COVID-19 patients (median age 44.4 years, 58 males and 30 with comorbidities) admitted between 22 January 2020 and 15 March 2020. Each CXR was reviewed and scored by three radiologists in consensus using a 72-point COVID-19 Radiographic Score (CRS). Disease severity was determined by the need for supplemental oxygen and mechanical ventilation.

Results: Patients who needed supplemental oxygen $(\mathrm{n}=19,17.4 \%)$ were significantly older $(\mathrm{P}<0.001)$ and significantly more of them had co-morbidities $(\mathrm{P}=0.011)$. They also had higher $\mathrm{C}$-reactive protein $(\mathrm{CRP})$ $(\mathrm{P}<0.001)$, higher lactate dehydrogenase $(\mathrm{LDH})(\mathrm{P}<0.001)$, lower lymphocyte count $(\mathrm{P}<0.001)$ and lower hemoglobin $(\mathrm{Hb})(\mathrm{P}=0.001)$. Their initial $\left(\mathrm{CRS}_{\text {initial }}\right)$ and maximal CRS $\left(\mathrm{CRS}_{\max }\right)$ were higher $(\mathrm{P}<0.001)$. Adjusting for age and baseline hemoglobin, the AUROC of $\mathrm{CRS}_{\max }(0.983)$ was as high as $\mathrm{CRP}_{\max }(0.987)$ and higher than the AUROC for lymphocyte count ${ }_{\min }(0.897)$, and $\mathrm{LDH}_{\max }(0.900)$. The AUROC for $\mathrm{CRS}_{\text {initial }}$ was slightly lower (0.930). $\mathrm{CRS}_{\text {initial }} \geq 5$ had a sensitivity of $63 \%$ and specificity of $92 \%$ in predicting the need for oxygen, and $73 \%$ sensitivity and $88 \%$ specificity in predicting the need for mechanical ventilation. CRS between the $6^{\text {th }}$ and $10^{\text {th }}$ day from the onset of symptoms $\left(\mathrm{CRS}_{\mathrm{D} 6-10}\right) \geq 5$ had a sensitivity of $89 \%$ and specificity of $95 \%$ in predicting the need for oxygen, and $100 \%$ sensitivity and $86 \%$ specificity in predicting the need for mechanical ventilation.

Conclusions: Adjusting for key confounders of age and baseline $\mathrm{Hb}, \mathrm{CRS}_{\max }$ performed comparable to or better than laboratory markers in the diagnosis of severe disease. CXR performed between the $6^{\text {th }}$ and $10^{\text {th }}$ days from symptom onset was a better predictor of severe disease than CXR performed earlier at presentation. A benign clinical course was seen in CXR that were normal or had very mild abnormalities.

Keywords: Radiography; thoracic; viruses; pneumonia

Submitted May 06, 2020. Accepted for publication May 29, 2020.

doi: 10.21037 /qims-20-642

View this article at: http://dx.doi.org/10.21037/qims-20-642

\footnotetext{
^, ORCID: Terrence C. H. Hui, 0000-0002-6941-4442; Hau Wei Khoo, 0000-0002-9843-1567; Barnaby E. Young, 0000-0003-1010-2230; Yee Sin Leo: 0000-0003-4978-5825; David C Lye: 0000-0003-0324-0205; Cher Heng Tan: 0000-0003-3341-3111.
} 


\section{Introduction}

Severe acute respiratory syndrome coronavirus 2 (SARS$\mathrm{CoV}-2$ ) represents the third zoonotic novel coronavirus to cause potentially fatal human lower respiratory tract infection (1). As of 29 May 2020, more than 5.7 million COVID-19 cases and over 350,000 deaths have been reported globally (2).

Imaging plays an integral part in the diagnosis and management of COVID-19. Computed tomography (CT) has proven sensitive in detecting early imaging features of COVID-19 in settings where virological test kits have been limited or falsely negative (3-6). However, chest CT is not recommended in areas of low disease prevalence due to a substantial rate of false-positives (7).

Despite a lower sensitivity for pulmonary diseases compared with chest CT, chest radiography (CXR) is still widely utilised (8). In many hospitals, CXR is used to distinguish COVID-19 associated pneumonia from an isolated upper respiratory tract infection $(8,9)$. Bedside imaging with mobile units minimises risk for nosocomial transmission of the virus. The American College of Radiology and the Fleischner Society both endorse the portability and easy cleaning of CXR compared to CT, for COVID-19 $(10,11)$.

However, CXR carries wide inter-observer variability as a diagnostic modality. In order to adequately study the utility of CXR, an objective method of determining the extent of lung changes should be used. During SARS, radiographic scores for CXR determined that the severity of CXR findings correlated well with the degree of hypoxia (12). Similarly, the Radiographic Assessment of Lung Edema (RALE) score was useful in gauging the severity of acute respiratory distress syndrome (ARDS) (13).

Despite the widespread use of CXR during this pandemic, there remains relatively little published data validating its role in clinical management. Given that our battle against COVID-19 may be a long-drawn, it is imperative that we define the role of CXR. We sought to assess the diagnostic performance of CXR, with emphasis on its predictive value, for severe COVID-19 disease which we defined as having the need for supplemental oxygen or mechanical ventilation. We present the following article in accordance with the STROBE guideline checklist.

\section{Methods}

A retrospective cohort study of all patients with COVID-19 patients admitted to the National Centre of Infectious Disease Singapore (NCID) between 22 January 2020 and 15
March 2020 was performed. Waiver of informed consent for data collection was obtained from the Ministry of Health, Singapore as part of the COVID-19 outbreak investigation. In Singapore, primary care doctors are directed to refer patients to National Centre for Infectious Diseases for screening for COVID-19 based on continually updated case definitions informed by evolving epidemiology. Symptomatic patients may also present themselves to any public hospital via its emergency department.

\section{Patients}

A total of 109 patients with SARS-CoV-2 infection confirmed by real-time reverse transcriptase polymerase chain reaction (RT-PCR) and followed-up for at least 3 weeks (21 days) were studied. At baseline, patients underwent CXR and blood investigations including complete blood count, renal and liver function tests, C-reactive protein (CRP) and lactate dehydrogenase (LDH). Complete blood count, CRP, LDH and CXR were repeated at intervals to monitor disease progression.

Patients' demographics and clinical features were collected from electronic medical records. Patients' data such as age, gender, smoking history, dates of symptom onset and hospital admission were collected. Relevant clinical features collected were body temperature and oxygen saturation $\left(\mathrm{SpO}_{2}\right)$, serum CRP, serum LDH. A standardised case report form modified from ISARIC was used to collate this data (14).

Daily nasopharyngeal samples for RT-PCR for SARS$\mathrm{CoV}-2$ were taken to document cessation of viral shedding; two negative PCR's 24 hours apart were required before deisolation and hospital discharge. Empiric broad-spectrum antibiotics and oseltamivir were prescribed for suspected community-acquired pneumonia, which were ceased if no bacterial cause or influenza was detected. In the absence of an effective anti-viral, treatment was largely supportive with supplemental oxygen administered if oxygen saturation by pulse oximetry was $\leq 94 \%$. Corticosteroids were avoided given inconsistent data and potential harm in SARS-CoV (15).

\section{Chest radiographs}

All CXR images, including portable CXR, were acquired on digital radiography units, and exported from Picture Archiving and Communication System in Digital Imaging and Communications in Medicine format in an anonymized format. All CXRs were retrospectively reviewed on a 

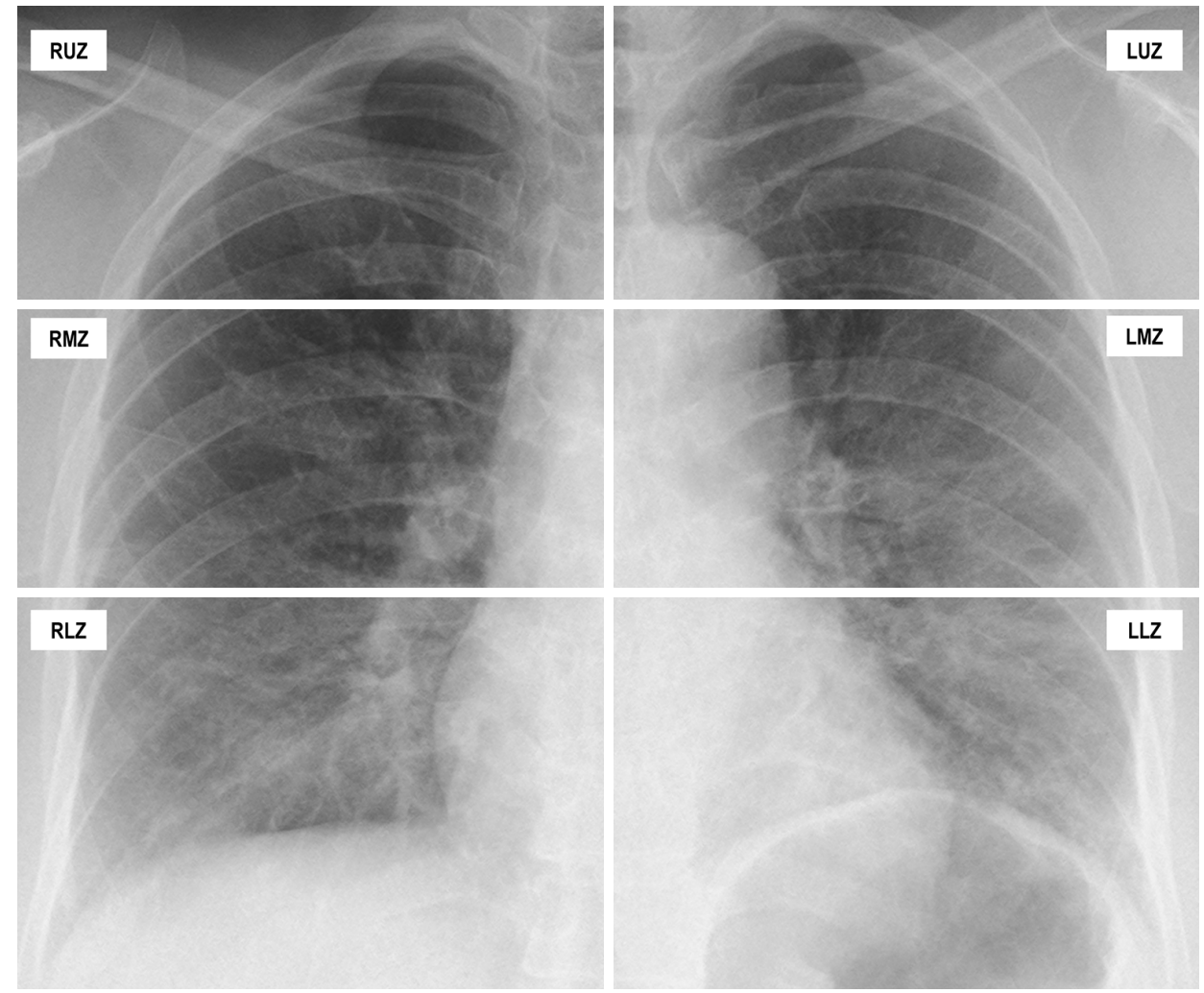

Figure 1 How COVID-19 Radiographic Score was calculated in the initial chest radiograph of a 71-year-old Chinese man with COVID-19: the patient had a past medical history of hypertension and presented to our institution with fever, shortness of breath and diarrhoea (day 6 of symptoms onset). On CXR, the right upper zone was graded 0 (no opacity), right middle zone was graded 1 ( $<25 \%$ opacity) with grade 1 density (hazy), right lower zone was graded 3 (50-74\% opacity) with grade 2 density, left upper zone was graded 0, left middle zone was graded 1 (<25\% opacity) with grade 1 density (hazy), left lower zone was graded 4 with grade 2 density. A CRS of $16(1+6+1+8)$ was obtained. The patient's oxygen saturation was $93 \%$ on arrival and he was started on supplemental oxygen. The patient's disease worsened and he was intubated on day 9 of symptom onset.

2,048×2,048-pixel DICOM monitor (Barco, Sunnyvale, CA, USA) by 3 subspecialty-trained radiologists and the CXRs were graded in consensus. The readers were blinded in their review from the subjects' clinical outcome and the CXRs were randomised. CXRs that were technically suboptimal were highlighted by our readers and excluded. The radiographs were first determined to be 'normal' or 'abnormal'. A 'normal' radiograph was defined as devoid of opacity in the lung fields and absence of ancillary findings such as pleural effusion and pneumothorax. Radiographs with opacities were deemed 'abnormal' and assessed for predominant pattern and distribution of opacities. The predominant pattern of opacities may be consolidation (homogeneous opacification, obscuring the blood vessels), ground-glass (hazy opacity without obscuring the blood vessels), nodular (focal round opacities) or reticular opacities (linear opacities). An opacity was considered central if it was within $2 / 3$ of the hilum, peripheral if it was in the outer $1 / 3$ of the hemithorax, or mixed if it involved both regions.

An objective COVID-19 Radiographic Score (CRS) was calculated for each CXR modified from the RALE score to account for the extent and density of airspace opacification (13). Each lung field was divided into three zones (upper, middle, lower); each zone spans one-third of the lung field craniocaudally. Each lung zone was scored for extent of airspace opacities (Grade 0, no opacity; Grade 1, $<25 \%$ opacity; Grade 2, 25-49\% opacity; Grade 3, 50-74\% opacity; Grade 4, >75\% opacity). The density of the opacity was scored [Grade 0, clear; Grade 1, hazy (vessel markings clearly visible); Grade 2, moderate (vessel markings are partially obscured); Grade 3, dense (vessels are obscured, air-bronchograms may be present)]. Figure 1 illustrates how 

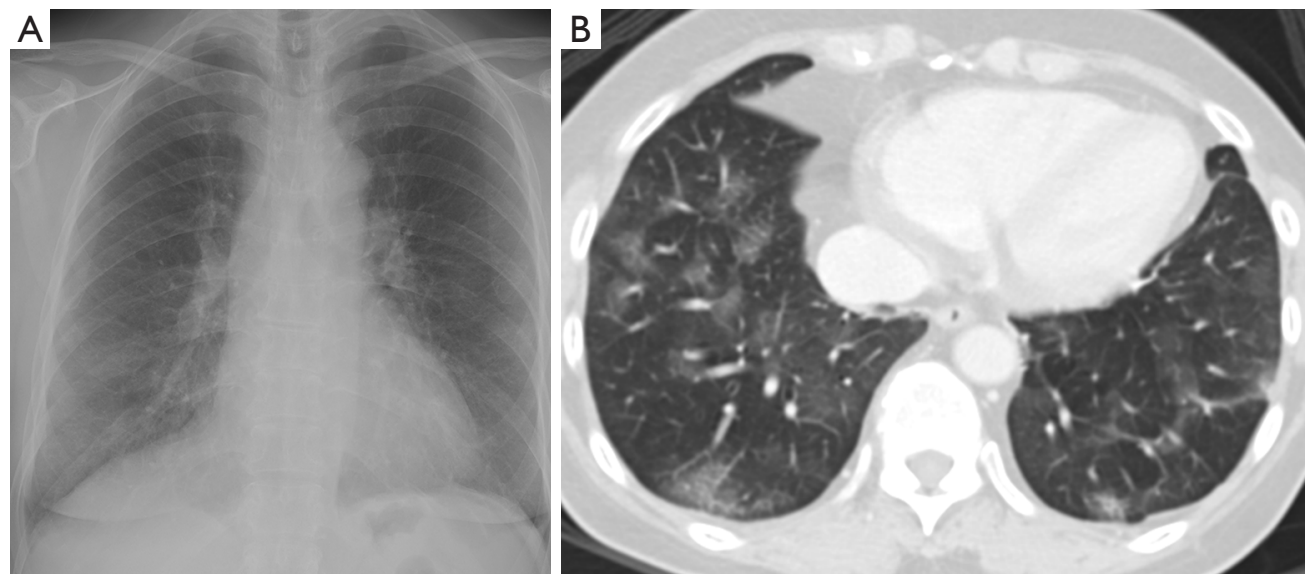

Figure 2 Correlation of ground-glass opacities between CXR and CT: a 36-year-old Chinese woman with no past medical history, who presents to hospital on day 6 of COVID-19 infection. (A) Chest radiograph on day 14 from symptom onset was scored as follows: right upper zone grade 1 with grade 1 density, right lower zone grade 2 with grade 1 density, left middle zone grade 1 with grade 1 density and left lower zone grade 1 with grade 1 density, CRS score of 5; (B) CT abdomen and pelvis performed on day 15, for abdominal pain, confirmed patchy ground-glass attenuation of the lower lobes, worse on the right. CXR, chest radiography.
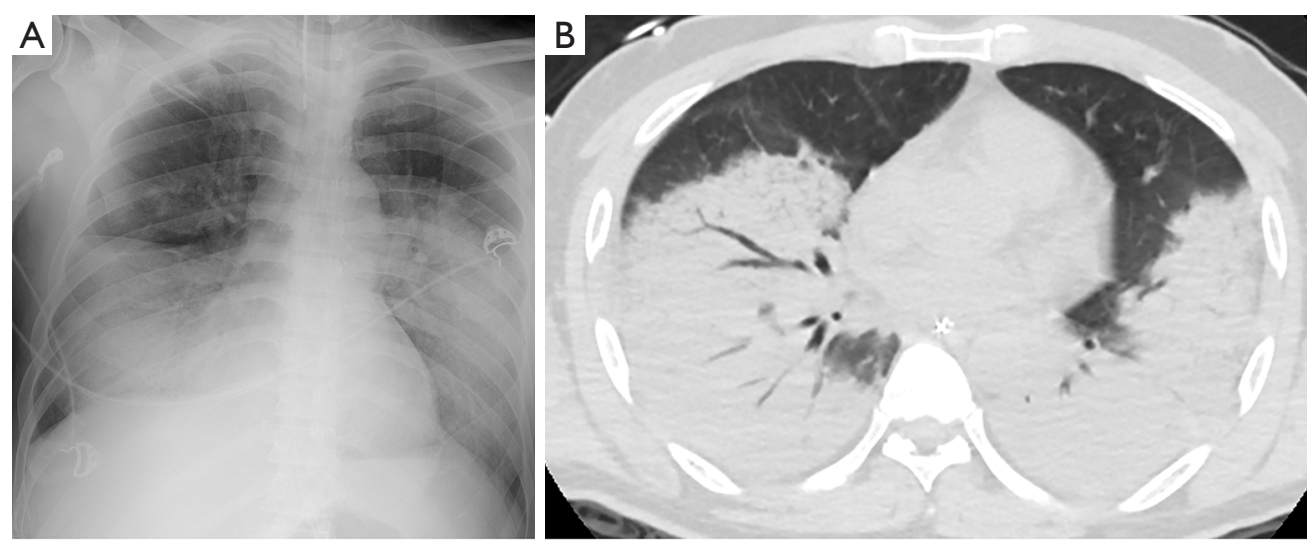

Figure 3 Correlation of consolidation between CXR and CT: a 68-year-old Chinese man with COVID-19, and relevant past medical history of smoking and hypertension, presented with shortness of breath on day 14 of symptom onset. He presented with an oxygen saturation of $85 \%$ on room air and was intubated on arrival. (A) Initial chest radiograph was scored as follows: right middle zone grade 1 density score 2 , right lower zone grade 3 density score 3, left middle zone grade 4 density score 3 and left lower zone grade 4 density score 2 (CRS 31 ); (B) CT thorax done on the same date confirmed dense consolidation in both lungs, worse in the lower lobes.

the score was tabulated. Figure 2 and Figure 3 illustrate how radiographic findings correlate with CT. For each zone, the extent of involvement was multiplied by the density yielding a score upon 12. The sum of the scores of each zone was tabulated to give a total score upon 72 .

\section{Statistical analysis}

The primary study endpoint was the need for supplemental oxygen and mechanical ventilation with intensive care unit (ICU) admission. The difference in clinical parameters with the need for supplemental oxygen was explored using Independent sample $t$-test, Mann Whitney $\mathrm{U}$ test, Pearson Chi-square, and Fisher Exact test, whichever appropriate after assumptions checking. Spearman correlation test was used to check the correlation between maximum CRS $\left(\mathrm{CRS}_{\max }\right)$, maximum CRP $\left(\mathrm{CRP}_{\max }\right)$, maximum LDH $\left(\mathrm{LDH}_{\max }\right)$ and lowest lymphocyte count (lymphocyte 
count $\left._{\min }\right)$. The diagnostic performances of CRS and laboratory markers were assessed with a logistic regression model. We adjusted for age and baseline hemoglobin $(\mathrm{Hb})$, as these are variables that potentially affect patients' baseline respiratory reserve and are deemed significant confounders. We analysed the sensitivity, specificity, positive predictive values and negative predictive values of CRS at initial presentation $\left(\mathrm{CRS}_{\text {initial }}\right)$ and on the $6-10^{\text {th }}$ day from onset of symptoms $\left(\mathrm{CRS}_{\mathrm{D} 6-10}\right) . \mathrm{CRS}_{\mathrm{D} 6-10}$ is defined as the CRS score for the CXR done between days 6 and 10 from the date of symptom onset. Statistical analysis was performed using IBM SPSS version 19.0 (IBM Corp, Armonk, NY). All statistical tests were two-sided and a p-value $<0.05$ was considered statistically significant.

\section{Results}

\section{Demographics}

Characteristics of the 109 patients on hospital admission with a comparison of baseline data between patients with and without supplemental oxygen are summarised in Table 1. Briefly, the median age was 44.4 years (SD, 14.5) and 58 $(53.2 \%)$ were men. Thirty (27.5\%) had comorbidities and the median time from symptom onset to admission was 4 [interquartile range (IQR), 1, 8] days.

\section{Clinical characteristics}

Eight patients required oxygen at presentation, 3 of whom were intubated at presentation. Another 11 desaturated subsequently during hospitalisation; there was 1 death. The most common symptoms at initial presentation were fever $(72.4 \%)$, cough $(68.9 \%)$ and sore throat $(44.0 \%)$; diarrhea was reported in $17.4 \%$. Two patients were asymptomatic $(1.8 \%)$. Patients who needed supplemental oxygen were significantly older $(\mathrm{P}<0.001)$, and had comorbidities $(\mathrm{P}=0.011)$, higher body temperature $(\mathrm{P}<0.001)$, heart rate $(\mathrm{P}=0.027)$ and respiratory rate $(\mathrm{P}=0.002)$ at presentation.

\section{CXR findings}

A total of 358 CXRs were performed on our study population (mean, 3; range, 1-32). The median time from symptom onset to first CXR was 4 (IQR, 1,7 ) days. The initial CXR was normal in 69 patients $(63.3 \%)$. Of the 40 abnormal initial CXRs, 17 showed consolidation pattern,
22 showed ground glass pattern and 1 showed a nodular pattern. The patterns of distribution were mixed peripheral and central $(n=26)$, peripheral $(n=9)$ and central $(n=5)$. Regarding the distribution of opacities, 13 were unifocal, 3 were multifocal unilateral and 24 were multifocal bilateral. Of the patients with an initial normal CXR $(n=69), 15$ developed an abnormal CXR during admission. Median time from $1^{\text {st }}$ normal CXR to $1^{\text {st }}$ abnormal CXR was 5 (IQR, 3, 7) days. Four patients who had initial normal CXR needed supplemental oxygen, of whom 2 required intubation and ICU admission. Fifty-four patients had normal CXRs throughout the admission and none of these patients required supplemental oxygen. Of the 55 patients with at least 1 abnormal CXR, 1 patient remained asymptomatic and had a $\mathrm{CRS}_{\max }$ of 4 . Among the 109 COVID-19 patients, only 7 had CT thorax performed during the course of admission, but imaging did not alter the clinical management significantly.

\section{Correlation of CRS with laboratory markers}

The median $\mathrm{CRS}_{\max }$ was 5.0 (IQR, 2.0, 23.0) and the median time from symptom onset to $\mathrm{CRS}_{\max }$ was 9 days (IQR, 5, 12). The results of the Spearman's Rank correlation tests are shown in Figure 4. Significant positive correlation was observed between $\mathrm{CRS}_{\max }$ and $\mathrm{CRP}_{\max }$ (spearman rho: 0.738; $\mathrm{P}<0.001$ ) and between $\mathrm{CRS}_{\text {max }}$ and $\mathrm{LDH}_{\max }$ (spearman rho: $0.604 ; \mathrm{P}<0.001)$. Significant inverse correlation was observed between $\mathrm{CRS}_{\max }$ and lowest lymphocyte count (spearman rho: $-0.478 ; \mathrm{P}<0.001$ ).

\section{Association of CRS and laboratory markers with clinical endpoints}

On initial laboratory tests, patients who needed supplemental oxygen had higher CRP $(\mathrm{P}<0.001), \mathrm{LDH}$ $(\mathrm{P}<0.001)$ and lower lymphocyte count $(\mathrm{P}<0.001)$. These patients also had significantly lower $\mathrm{Hb}(\mathrm{P}=0.001)$ and platelet count $(\mathrm{P}=0.018)$ (Table 1). Comparison of CRS values, $\mathrm{CRP}_{\text {max }}, \mathrm{LDH}_{\text {max }}$ and lymphocyte count ${ }_{\text {min }}$ between patients who needed supplemental oxygen versus those who did not are shown in Table 2. Patients who needed supplemental oxygen had higher $\mathrm{CRS}_{\text {initial }}(\mathrm{P}<0.001), \mathrm{CRS}_{\max }$ $(\mathrm{P}<0.001), \mathrm{CRP}_{\max }(\mathrm{P}<0.001)$ and $\mathrm{LDH}_{\max }(\mathrm{P}<0.001)$. They also had a lower lymphocyte count ${ }_{\min }(\mathrm{P}<0.001)$. Among patients who needed supplemental oxygen, $\mathrm{CRS}_{\max }$ was significantly higher in the ICU group versus the non-ICU group (mean CRS 37.6 versus 17.8 respectively, $\mathrm{P}=0.001$ ). 
Table 1 Characteristics of patients with COVID-19 on hospital admission

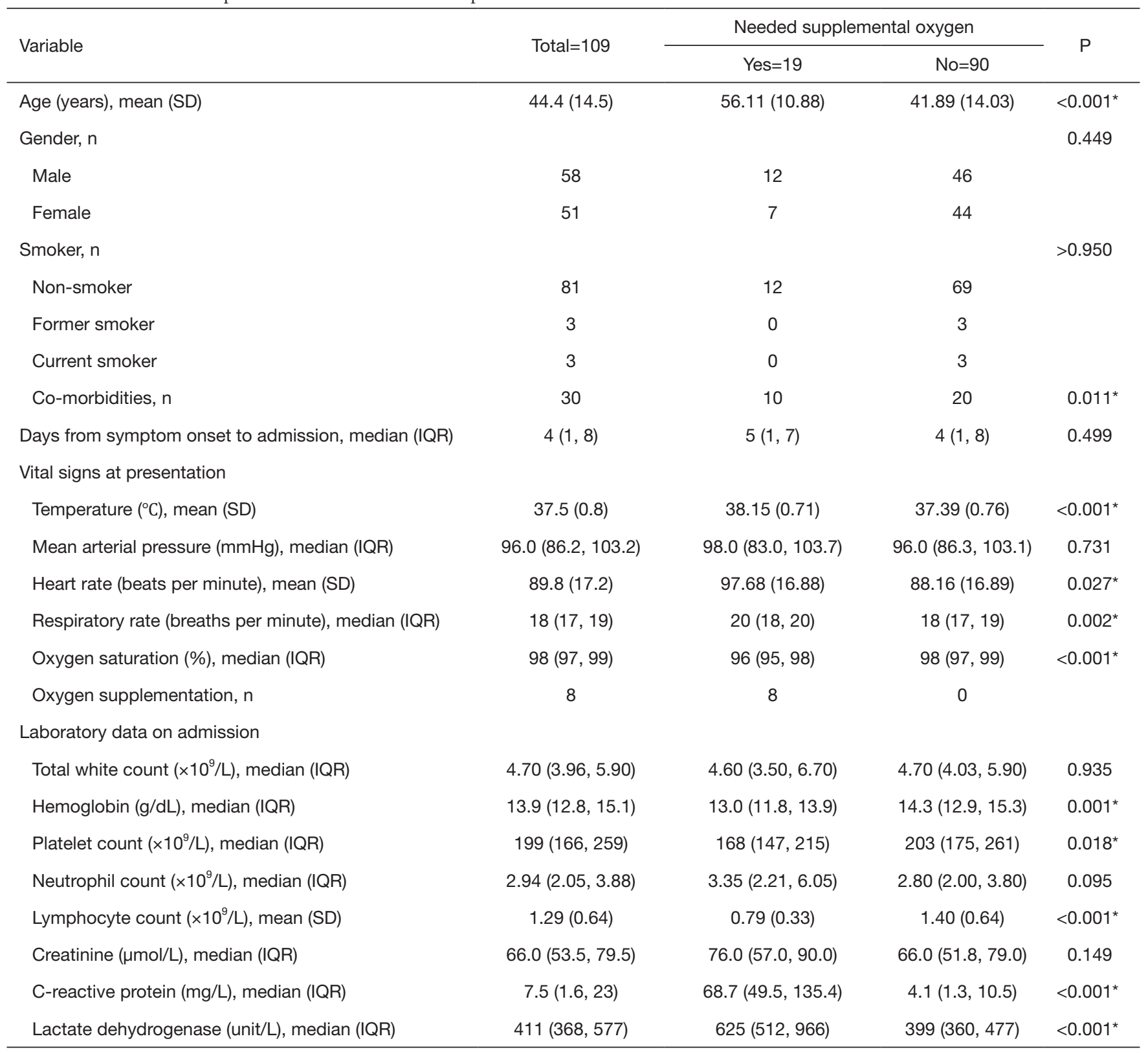

${ }^{*}$, denotes statistically significant differences between patients with and without supplemental oxygen. P-value of $<0.05$ is considered statistically significant.

\section{Diagnostic performance of CRS and laboratory markers}

The area under receiver operating characteristic curves (AUROC) of lymphocyte count $t_{\min }, \mathrm{CRP}_{\max }, \mathrm{LDH}_{\max }$, $\mathrm{CRS}_{\text {initial }}$ and $\mathrm{CRS}_{\max }$ as markers for supplemental oxygen requirement, adjusted for age and baseline $\mathrm{Hb}$, are shown in Table 3. CRS $_{\max }$ (AUROC 0.983) had diagnostic performance as high as, if not higher, than the laboratory markers in determining the need for supplemental oxygen. $\mathrm{CRS}_{\text {initial }}$ (AUROC 0.930) performed less well than $\mathrm{CRS}_{\max }$.

\section{Use of CRS for predicting clinical outcomes}

About $81.7 \%$ (89/109) patients had $\mathrm{CRS}_{\text {initial }}<5,7.9 \%$ of these patients $(7 / 89)$ needed supplemental oxygen and 

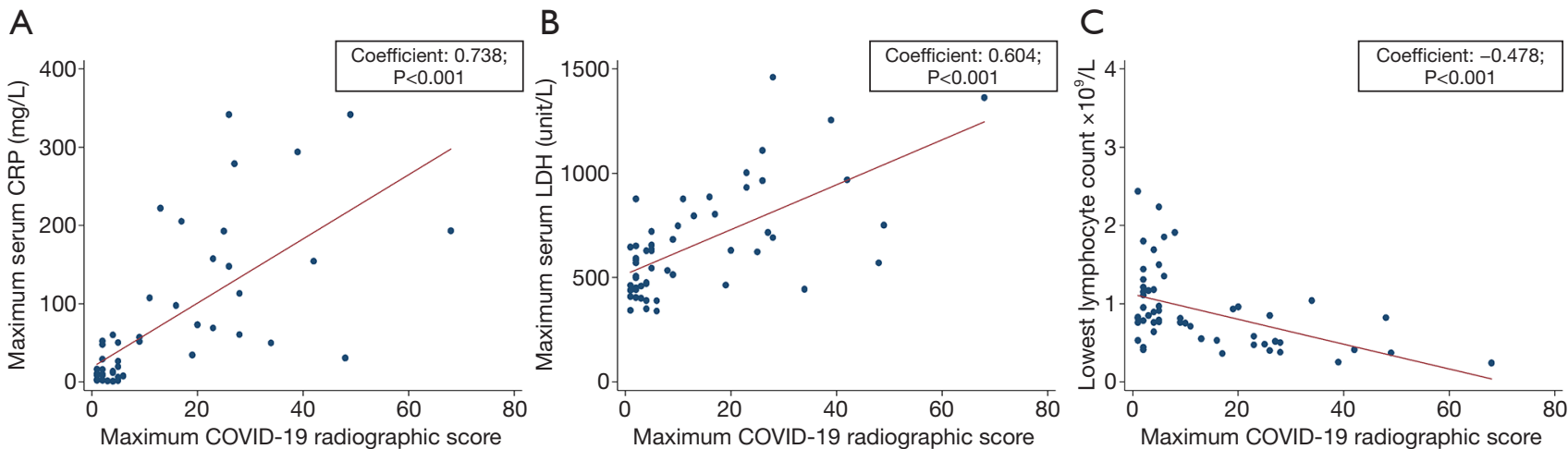

Figure 4 Scatterplot diagrams illustrate relationships between maximum COVID-19 Radiographic Score and (A) maximum CRP, (B) maximum LDH and (C) lowest lymphocyte count. CRP, C-reactive protein; LDH, Lactate dehydrogenase.

Table 2 COVID-19 Radiographic Scores and known severity markers for patients with COVID-19

\begin{tabular}{|c|c|c|c|c|}
\hline \multirow{2}{*}{ Variables } & \multirow{2}{*}{ Total=109 } & \multicolumn{2}{|c|}{ Needed supplemental oxygen } & \multirow{2}{*}{$\mathrm{P}$} \\
\hline & & Yes $=19$ & $\mathrm{No}=90$ & \\
\hline \multicolumn{5}{|l|}{ COVID-19 Radiographic Score } \\
\hline $\mathrm{CRS}_{\text {initial, }}$, median (IQR) & $0.0(0.0,3.0)$ & $9.0(2.0,17.0)$ & $0.0(0.0,1.0)$ & $<0.001^{*}$ \\
\hline $\mathrm{CRS}_{\max }$, median (IQR) & $5.0(2.0,23.0)$ & $26.0(20.0,39.0)$ & $4.0(2.0,5.0)$ & $<0.001^{*}$ \\
\hline Lymphocyte count $_{\min }\left(\times 10^{9} / L\right)$, mean (SD) & $1.19(0.64)$ & $1.32(0.62)$ & $0.56(0.24)$ & $<0.001^{\star}$ \\
\hline $\mathrm{CRP}_{\max }(\mathrm{mg} / \mathrm{L})$, median $(\mathrm{IQR})$ & $8.5(1.8,49.0)$ & $4.7(1.6,15.4)$ & $154.0(68.7,222.3)$ & $<0.001^{*}$ \\
\hline $\mathrm{LDH}_{\max }$ (unit/L), mean (SD) & $534.8(235.3)$ & $460.0(140.2)$ & $865.6(285.2)$ & $<0.001^{*}$ \\
\hline
\end{tabular}

*, denotes statistically significant differences between patients with and without supplemental oxygen. P-value of $<0.05$ is considered statistically significant. CRS $_{\text {initial }}$, COVID-19 Radiographic Score on initial chest radiograph; CRS $_{\max }$, maximum COVID-19 Radiographic Score; $\mathrm{CRP}_{\max }$, maximum C-reactive protein; $\mathrm{LDH}_{\max }$, maximum Lactate dehydrogenase; Lymphocyte count min $_{\text {minimum lymphycyte }}$ count.

Table 3 Diagnostic performance of Maximum CRS and laboratory markers to determine the need for supplemental oxygen adjusted for age and $\mathrm{Hb}$

\begin{tabular}{|c|c|c|c|c|c|}
\hline Variables & Negelkerke R square & Adjusted OD & $95 \% \mathrm{Cl}$ & $P$ value & AUROC \\
\hline $\mathrm{CRS}_{\max }$ & 0.869 & 1.442 & $1.143,1.821$ & $0.002^{*}$ & 0.983 \\
\hline $\mathrm{CRP}_{\max }$ & 0.816 & 1.055 & $1.018,1.094$ & $0.004^{*}$ & 0.987 \\
\hline $\mathrm{LDH}_{\max }$ & 0.487 & 0.050 & $0.007,0.353$ & $0.003^{*}$ & 0.900 \\
\hline
\end{tabular}

${ }^{*}$, denotes statistically significant differences between patients with and without supplemental oxygen. P-value of $<0.05$ is considered statistically significant. CRSmax, maximum COVID-19 Radiographic Score; CRP $_{\max }$, maximum C-reactive protein; LDHmax, maximum lactate dehydrogenase; Lymphocyte count ${ }_{\text {min }}$, minimum lymphycyte count. 
Table 4 COVID-19 Radiographic Score on initial CXR: Comparison between CRS $S_{\text {initial }}$ at cut-off of 0 versus CRS $_{\text {initial }}$ at cut-off of 5

\begin{tabular}{lccccc}
\hline CRS $_{\text {initial }}$ & Clinical outcome & Sensitivity & Specificity & PPV & NPV \\
\hline Cut-off $=0$ & Supplemental $\mathrm{O}_{2}$ & $78.95(71.29,86.60)$ & $72.22(63.81,80.63)$ & $37.50(28.41,46.59)$ & $94.20(89.82,98.59)$ \\
& ICU & $81.82(74.58,89.06)$ & $68.37(59.64,77.10)$ & $22.50(14.66,30.34)$ & $97.10(93.95,100.00)$ \\
Cut-off $<5$ & Supplemental O & $63.16(54.10,72.21)$ & $91.11(85.77,96.45)$ & $60.00(50.80,69.20)$ & $92.13(87.08,97.19)$ \\
& ICU & $72.73(64.37,81.09)$ & $87.76(81.60,93.91)$ & $40.00(30.80,49.20)$ & $96.63(93.24,100.00)$ \\
\hline
\end{tabular}

$\mathrm{CRS}_{\text {initial }}$, COVID-19 Radiographic Score on initial chest radiograph; PPV, positive predictive value, NPV, negative predictive value.

Table 5 COVID-19 Radiographic Score on day 6-10 from symptom onset: Comparison between $\mathrm{CRS}_{\mathrm{D} 6-10}$ at cut-off of 0 versus CRS ${ }_{\mathrm{D} 6-10}$ at cutoff of 5

\begin{tabular}{lccccc}
\hline CRS $_{\text {D6-10 }}$ & Clinical outcome & Sensitivity & Specificity & PPV & NPV \\
\hline Cut-off $=0$ & Supplemental O & $94.44(88.74,100.00)$ & $63.64(51.66,76.61)$ & $51.52(39.08,63.96)$ & $96.55(92.01,100.00)$ \\
& ICU & $100.00(100.00,100.00)$ & $56.86(44.53,69.19)$ & $33.33(21.60,45.07)$ & $100.00(100.00,100.00)$ \\
Cut-off $<5$ & Supplemental O & $88.89(81.07,96.71)$ & $95.45(90.27,100.00)$ & $88.89(81.07,96.71)$ & $95.45(90.27,100.00)$ \\
& ICU & $100.00(100.00,100.00)$ & $86.27(77.71,94.84)$ & $61.11(48.98,73.25)$ & $100.00(100.00,100.00)$
\end{tabular}

$\mathrm{CRS}_{\mathrm{D} 6-10}$, COVID-19 Radiographic Score day 6-10 from symptom onset; PPV, positive predictive value; NPV, negative predictive value.

$3(3.4 \%)$ needed intubation and ICU admission. Of the 20 patients $(18.3 \%)$ with $\mathrm{CRS}_{\text {initial }} \geq 5,12(60 \%)$ required supplemental oxygen and $8(40 \%)$ needed intubation and ICU admission. The comparison between $\mathrm{CRS}_{\text {initial }}$ at cutoff of 0 versus cut-off of 5 is shown in Table $4 . \mathrm{CRS}_{\text {initial }} \geq 5$ had a sensitivity of $63 \%$ and specificity of $92 \%$ in predicting the need for oxygen, and $73 \%$ sensitivity and $88 \%$ specificity in predicting the need for ICU admission. The comparison between $\mathrm{CRS}_{\mathrm{D} 6-10}$ at cut-off of 0 versus cut-off of 5 is shown in Table 5. Sixty-two patients had a CXR done between days 6 and 10 of symptom onset. $\mathrm{CRS}_{\mathrm{D} 6-10} \geq 5$ had a sensitivity of $89 \%$ and specificity of $95 \%$ in predicting the need for oxygen and $100 \%$ sensitivity and $86 \%$ specificity in predicting the need for ICU admission.

\section{Discussion}

The extent of lung involvement on CT imaging has been shown to correlate with the clinical outcome and prognosis of COVID-19. Yang et al. described a CT severity score which proved to be accurate in identifying severe COVID-19 infection (AUROC, 0.892; sensitivity, $83.3 \%$, specificity, $94.0 \%$ ) (16). Colombi et al. used software quantification of the extent of CT lung abnormality on initial CT to predict ICU admission or death (AUC, 0.86 ) in 236 patients (17). Inui et al. found that among the COVID-19 patients on "Diamond Princess" cruise ship, asymptomatic cases showed more ground-glass opacities over consolidation $(83 \%)$ while symptomatic cases more frequently showed consolidation over ground glass opacities (41\%) (18). In that series, only $54 \%$ of asymptomatic cases had CT findings. The limited sensitivity of CT for well patients is further iterated in the report by $\mathrm{Xu}$ et al., who described an extended family cluster of COVID-19 who were asymptomatic or had mainly mild symptoms and negative CTs (19). Thus, in ours and many other practices around the world, CT has been used sparingly, reserved for patients in whom other underlying etiologies, such as pulmonary embolism, need to be excluded (20). The clinical value of CXR for this new infectious agent remains to be elucidated.

The RALE and its modifications have been used to monitor the progression of disease $(8,13)$. For our study, we modified RALE from a maximum score of 48 to 1 of 72 , by dividing the lung into 6 zones rather than 4 , as per routine clinical interpretation. As CXR is a two-dimensional representation of the lungs, we further included density to the scoring system to more accurately account for the anteroposterior extent of disease. Although this was more laborious, the COVID-19 Radiographic Score (CRS) has allowed us to grade the extent and severity of lung disease on CXR.

Our study shows that CXR severity (based on CRS) correlated with known laboratory markers of disease 
severity. Higher LDH, higher CRP and lower lymphocyte count have been observed in patients with severe COVID-19 infection, requiring supplemental oxygen and/ or ICU admission (21-25). We found significant positive correlation between $\mathrm{CRS}_{\max }$ and $\mathrm{CRP}_{\max }$ and $\mathrm{LDH}_{\max }$, and a significant inverse correlation between $\mathrm{CRS}_{\max }$ and lymphocyte count min $_{\text {min }}$.

More importantly, CRS correlated with our defined clinical endpoint of supplemental oxygen requirement, including admission to ICU for mechanical ventilation. The median time from symptom onset to maximum CRS score was 9 (IQR, 5, 12) days. This is similar to the findings by Wong et al, who found peak radiographic scores at a median of 10 days after symptom onset (8). Salehi et al. found that the greatest severity of CT findings was seen on day 10 from symptom onset (26). This is consistent with the clinical course of COVID-19. Zhou et al. found median time from illness onset to sepsis and ARDS to be 10 (IQR, 7, $14)$ days and 12 (IQR, 8, 15) days respectively (27).

Since age and baseline hemoglobin are close determinants of respiratory reserve, we performed a comparison of AUROC after adjustment of these two variables. We found that $\mathrm{CRS}_{\max }$ yielded the highest diagnostic performance for our defined clinical endpoints (AUROC, 0.983). This suggests that CXR severity using the CRS may be as useful as if not more than laboratory markers for determining severity of pneumonia, making it a reasonable diagnostic tool for monitoring patients in the community setting.

All our patients had a CXR at presentation. The median time from symptom onset to first CXR was 4 (IQR, 1, 7) days and most $(81.7 \%)$ had CXR which were normal or with very mild findings on arrival $\left(\mathrm{CRS}_{\text {initial }}<5\right)$. Two other authors found a similar high rate of between $72-89 \%$ of patients with normal or only mildly abnormal CXR on arrival $(8,28)$.

$\mathrm{CRS}_{\mathrm{D} 6-10}$ was better able to predict for need for supplemental oxygen and ICU with higher sensitivity and specificity than $\mathrm{CRS}_{\text {initial }}$. This is in keeping with the fact that CXR may not manifest significant changes early in the course of disease (8). By raising the cut-off from 0 to 5 , we found that the PPV and specificity of $\mathrm{CRS}_{\mathrm{D} 6-10}$ increased, with relative preservation of NPV and sensitivity (Table 5). In practice, given that COVID-19 most commonly presents with multifocal opacities, CRS of less than 5 would be the equivalent of ground-glass (hazy) opacities involving less than $50 \%$ of the lower zones of each lung or other similar permutations that would be deemed "very mild". This eliminates a number of "false positive" abnormalities that resolve without need for close monitoring or supplemental oxygen (8). A recent report by Yang et al. showed that the use of a CT severity score yielded an NPV of 96.3\% (16). The high NPV (92.1\%) that we have observed with $\mathrm{CRS}_{\mathrm{D} 6-10}$ suggests that CXR may suffice for excluding severe COVID-19 pneumonia beyond one week from symptom onset, without the need for CT.

There are several limitations to our study: (I) CXR was performed based upon clinical need and patients who were well had fewer CXR than in those requiring supplemental oxygen. Patients in the latter group had a mean of 8 radiographs while patients in the former group had a mean of 2 radiographs performed during their admission. To reduce bias, our raters were blinded to the laboratory and clinical endpoints during their evaluation of the CXR images; (II) we chose not to study the relationship between CRS and length of stay of patients because the decision to discharge patients from the hospital was based upon satisfying the criterion of two consecutive negative RTPCR tests, which frequently post-dated clinical recovery; (III) our readers were subspecialty-trained radiologists with at least 10 years of experience reading CXR and future studies may be performed to validate CRS at lower levels of expertise. However, the detailed methodology of CRS was designed to increase the objectivity of assessment; (IV) due to the practice pattern in Singapore with a relatively low rate of CT scanning, we were not able to directly compare the accuracy of CXR versus CT for prediction of need for supplemental oxygen, which may be helpful to address reported discordance between severity on CT with clinical parameters (29).

In conclusion, the degree of CXR abnormalities reflected disease severity comparable to or better than laboratory markers. CXR performed between the $6^{\text {th }}$ and $10^{\text {th }}$ days from symptom onset was a better predictor of severe disease than CXR performed earlier at presentation. A benign clinical course was seen in CXR that were normal or had very mild abnormalities.

\section{Acknowledgements}

We thank all clinical and nursing staff who provided care for the patients at National Centre for Infectious Diseases and staff in Singapore Infectious Disease Clinical Research Network and Infectious Disease Research and Training Office, National Centre for Infectious Diseases for coordinating patient recruitment.

Funding: None. 


\section{Footnote}

Conflicts of Interest: All authors have completed the ICMJE uniform disclosure form (available at http://dx.doi. org/10.21037/qims-20-642). The authors have no conflicts of interest to declare.

Ethical Statement: Waiver of informed consent for data collection was obtained from the Ministry of Health, Singapore as part of the COVID-19 outbreak investigation.

Open Access Statement: This is an Open Access article distributed in accordance with the Creative Commons Attribution-NonCommercial-NoDerivs 4.0 International License (CC BY-NC-ND 4.0), which permits the noncommercial replication and distribution of the article with the strict proviso that no changes or edits are made and the original work is properly cited (including links to both the formal publication through the relevant DOI and the license). See: https://creativecommons.org/licenses/by-nc-nd/4.0/.

\section{References}

1. Zhu N, Zhang D, Wang W, Li X, Yang B, Song J, Zhao X, Huang B, Shi W, Lu R, Niu P, Zhan F, Ma X, Wang D, Xu W, Wu G, Gao GF, Tan W; China Novel Coronavirus Investigating and Research Team. A Novel Coronavirus from Patients with Pneumonia in China, 2019. N Engl J Med 2020;382:727-33.

2. World Health Organization. Coronavirus disease 2019 (COVID-19) Situation Report.-91. 2020. Available online: https://www.who.int/docs/default-source/ coronaviruse/situation-reports/20200420-sitrep-91covid-19.pdf?sfvrsn=fcf0670b_4

3. Ai T, Yang Z, Hou H, Zhan C, Chen C, Lv W, Tao Q, Sun Z, Xia L. Correlation of Chest CT and RT-PCR Testing in Coronavirus Disease 2019 (COVID-19) in China: A Report of 1014 Cases. Radiology 2020. [Epub ahead of print]. doi: 10.1148/radiol.2020200642.

4. Zhang J, Zhou L, Yang Y, Peng W, Wang W, Chen $\mathrm{X}$. Therapeutic and triage strategies for 2019 novel coronavirus disease in fever clinics. Lancet Respir Med 2020;8:e11-2.

5. Duan YN, Qin J. Pre- and Posttreatment Chest CT Findings: 2019 Novel Coronavirus (2019-nCoV) Pneumonia. Radiology 2020;295:21.

6. Song F, Shi N, Shan F, Zhang Z, Shen J, Lu H, Ling Y, Jiang Y, Shi Y. Emerging Coronavirus 2019-
nCoV Pneumonia. Radiology 2020. doi: 10.1148/ radiol.2020200274.

7. Kim H, Hong H, Yoon SH. Diagnostic Performance of CT and Reverse Transcriptase-Polymerase Chain Reaction for Coronavirus Disease 2019: A Meta-Analysis. Radiology 2020. doi: 10.1148/radiol.2020201343.

8. Wong HYF, Lam HYS, Fong AH, Leung ST, Chin TW, Lo CSY, Lui MM, Lee JCY, Chiu KW, Chung T, Lee EYP, Wan EYF, Hung FNI, Lam TPW, Kuo M, Ng MY. Frequency and Distribution of Chest Radiographic Findings in COVID-19 Positive Patients. Radiology 2019. doi: 10.1148/radiol.2020201160.

9. The BMJ Option. Hare S, Rodrigues J, Nair A, Robinson G. Lessons from the frontline of the covid-19 outbreak. 2020. Available online: https://blogs.bmj.com/ bmj/2020/03/20/lessons-from-the-frontline-of-thecovid-19-outbreak/?utm_campaign=shareaholic\&utm_ medium=twitter\&utm_source=socialnetwork

10. American College of Radiology. ACR Recommendations for the use of Chest Radiography and Computed Tomography (CT) for Suspected COVID-19 Infection. 2020. Available online: https://www.acr.org/Advocacy-andEconomics/ACR-Position-Statements/Recommendationsfor-Chest-Radiography-and-CT-for-SuspectedCOVID19-Infection

11. Rubin GD, Ryerson CJ, Haramati LB, Sverzellati N, Kanne JP, Raoof S, Schluger NW, Volpi A, Yim JJ, Martin IBK, Anderson DJ, Kong C, Altes T, Bush A, Desai SR, Goldin J, Goo JM, Humbert M, Inoue Y, Kauczor HU, Luo F, Mazzone PJ, Prokop M, RemyJardin M, Richeldi L, Schaefer-Prokop CM, Tomiyama $\mathrm{N}$, Wells AU, Leung AN. The Role of Chest Imaging in Patient Management during the COVID-19 Pandemic: A Multinational Consensus Statement from the Fleischner Society. Chest 2020. [Epub ahead of print]. doi: 10.1016/ j.chest.2020.04.003.

12. Ooi CG, Khong PL, Lam B, Ho JC, Yiu WC, Wong WM, Wang T, Ho PL, Wong PC, Chan RH, Lam WK, Lai KN, Tsang KW. Severe acute respiratory syndrome: relationship between radiologic and clinical parameters. Radiology 2003;229:492-9.

13. Warren MA, Zhao Z, Koyama T, Bastarache JA, Shaver CM, Semler MW, Rice TW, Matthay MA, Calfee CS, Ware LB. Severity scoring of lung oedema on the chest radiograph is associated with clinical outcomes in ARDS. Thorax 2018;73:840-6.

14. COVID-19 Clinical Research Resources. ISARIC. 2020. Available online: https://isaric.tghn.org/covid-19-clinical- 
research-resources/

15. Stockman LJ, Bellamy R, Garner P. SARS: systematic review of treatment effects. PLoS Med 2006;3:e343.

16. Yang R, Li X, Liu Hu, Zhen Y, Zhang X, Xiong Q, Luo Y, Gao C, Zeng W. Chest CT Severity Score: An Imaging Tool for Assessing Severe COVID-19. Radiology 2020. doi: 10.1148/ryct.2020200047.

17. Colombi D, Bodini FC, Petrini M, Maffi G, Morelli N, Milanese G, Silva M, Sverzellati N, Michieletti E. Wellaerated Lung on Admitting Chest CT to Predict Adverse Outcome in COVID-19 Pneumonia. Radiology 2020. doi: 10.1148/radiol.2020201433.

18. Inui S, Fujikawa A, Jitsu Mo, Kunishima N, Watanabe S, Suzuki Y, Umeda S, Uwabe Y. Chest CT Findings in Cases from the Cruise Ship "Diamond Princess" with Coronavirus Disease 2019 (COVID-19). Radiology 2020. doi: $10.1148 /$ ryct.2020200110.

19. Xu R, Du M, Li L, Zhen Z, Wang H, Hu X. CT imaging of one extended family cluster of corona virus disease 2019 (COVID-19) including adolescent patients and "silent infection". Quant Imaging Med Surg 2020;10:800-4.

20. Lim ZY, Khoo HW, Hui TCH, Kok SSX, Kwan KEL, Young BE, Tan CH, Kaw GJL. Variable computed tomography appearances of COVID-19. Singapore Med J 2020. [Epub ahead of print]. doi:10.11622/smedj.2020066.

21. Huang C, Wang Y, Li X, Ren L, Zhao J, Hu Y, Zhang L, Fan G, Xu J, Gu X, Cheng Z, Yu T, Xia J, Wei Y, Wu W, Xie X, Yin W, Li H, Liu M, Xiao Y, Gao H, Guo L, Xie J, Wang G, Jiang R, Gao Z, Jin Q, Wang J, Cao B. Clinical features of patients infected with 2019 novel coronavirus in Wuhan, China. Lancet 2020;395:497-506.

22. Liu Z, Long W, Tu M, Chen S, Huang Y, Wang S, Zhou W, Chen D, Zhou L, Wang M, Wu M, Huang Q, Xu H, Zeng W, Guo L. Lymphocyte subset (CD4+, CD8+) counts reflect the severity of infection and predict the clinical outcomes in patients with COVID-19. J Infect 2020. [Epub ahead of print]. doi: 10.1016/j.jinf.2020.03.054.

23. Tan L, Wang Q, Zhang D, Ding J, Huang Q, Tang

Cite this article as: Hui TCH, Khoo HW, Young BE, Haja Mohideen SM, Lee YS, Lim CJ, Leo YS, Kaw GJL, Lye DC, Tan CH. Clinical utility of chest radiography for severe COVID-19. Quant Imaging Med Surg 2020;10(7):1540-1550. doi: 10.21037/qims-20-642
YQ, Miao H. Lymphopenia predicts disease severity of COVID-19: a descriptive and predictive study. Signal Transduct Target Ther 2020;5:33.

24. Wang D, Hu B, Hu C, Zhu F, Liu X, Zhang J, Wang B, Xiang H, Cheng Z, Xiong Y, Zhao Y, Li Y, Wang X, Peng Z. Clinical Characteristics of 138 Hospitalized Patients With 2019 Novel Coronavirus-Infected Pneumonia in Wuhan, China. JAMA 2020;323:1061-9.

25. Young BE, Ong SWX, Kalimuddin S, Low JG, Tan SY, Loh J, Ng OT, Marimuthu K, Ang LW, Mak TM, Lau SK, Anderson DE, Chan KS, Tan TY, Ng TY, Cui L, Said Z, Kurupatham L, Chen MI, Chan M, Vasoo S, Wang LF, Tan BH, Lin RTP, Lee VJM, Leo YS, Lye DC; Singapore 2019 Novel Coronavirus Outbreak Research Team. Epidemiologic Features and Clinical Course of Patients Infected With SARS-CoV-2 in Singapore. JAMA 2020;323:1488-94.

26. Salehi S, Abedi A, Balakrishnan S, Gholamrezanezhad A. Coronavirus Disease 2019 (COVID-19): A Systematic Review of Imaging Findings in 919 Patients. AJR Am J Roentgenol 2020;215:87-93.

27. Zhou F, Yu T, Du R, Fan G, Liu Y, Liu Z, Xiang J, Wang Y, Song B, Gu X, Guan L, Wei Y, Li H, Wu X, Xu J, Tu S, Zhang Y, Chen H, Cao B. Clinical Course and Risk Factors for Mortality of Adult Inpatients With COVID-19 in Wuhan, China: A Retrospective Cohort Study. Lancet 2020;395:1054-2.

28. Weinstock M, Echenique A, Russell J, Leib A, Miller J, Cohen D, Waite S, Frye A, Illuzzi F. Chest X-Ray Findings in 636 Ambulatory Patients with COVID-19 Presenting to an Urgent Care Center: A Normal Chest X-Ray Is no Guarantee. Available online: https://www.jucm.com/ documents/jucm-covid-19-studyepub-april-2020.pdf/

29. Zhang B, Zhang J, Chen H, Yang K, Zhang S. Unmatched Clinical Presentation and Chest CT Manifestation in a Patient With Severe Coronavirus Disease 2019 (COVID-19). Quant Imaging Med Surg 2020;10:871-3. 